\title{
Wind-Induced Clearances Infringement of Overhead Power Lines
}

\author{
Ali I. El Gayar, Zulkurnain Abdul-Malek, and Ibtihal Fawzi El-Shami
}

\begin{abstract}
This paper presents a methodical approach, suggestions and information to design $400 \mathrm{kV}$ transmission lines, check which types of towers, conductors and insulators are suitable to use based on wind velocity. as well as calculate the effect of wind on L12 tower top geometrics, and keep the probability of flashover very low. In this project, weather and climate are considered in the design of overhead lines. The purpose of this paper is to determine the clearances necessary for a $400 \mathrm{kV}$ line to withstand high wind velocity, and ensure that conductors have to maintain the clearances under lightning, switching and TOV (temporary over voltage). Excel and Visio are used to analyse the results and plot them, in order to find the swing angle of movement of the insulator and conductor, and the minimum clearances produced under certain wind speed. Finally, the return period per year and the probability of conductor infringes the clearances per year are calculated.
\end{abstract}

Index Terms $-400 \mathrm{kV}$ overhead power line, wind impact on L12 tower, design top geometries.

\section{INTRODUCTION}

Most overhead transmission lines are exposed to some natural phenomena such as wind, temperature and humidity, all of which can, directly or indirectly, cause a change in the tower top geometry and clearances. Owing to its tall structure, the overhead line tower is usually subjected to strong winds. As well as causing vibration in the conductors, high wind speeds can also cause the conductors to move closer to or away from the tower body [1], [2].

Both the insulator swing, as well as the conductor swing, reduces the clearances. The clearances between conductors and earth structures under the action of wind may also be of importance. The wind also affects the clearances between the conductors in mid-; span. The wind velocity is considered as the basis for tower structural design. The wind velocity may lead to the ultimate load, which may stress the structure to its maximum strength capacity. In addition, some other parameters should also be taken into consideration. These include the wind direction, time distribution of wind velocities, return period and maximum wind velocity [2]-[4].

For a given transmission line voltage, the design will take all aspects into consideration, including the wind-induced clearances infringement. Currently, the transmission network in Libya is rated at $270 \mathrm{kV}$. As a result of the increase in population and manufacturing activities, the transmission voltage is intended to be increased to $400 \mathrm{kV}$. However,

Manuscript received February 15, 2014; revised June 8, 2014.

The authors are with the Faculty of Electrical Engineering, College of Electrical and Electronics Technology-Benghazi, Universiti Teknologi Malaysia, Malaysia (e-mail: elgayar79@gmail.com, zulk@fke.utm.my, tola84_79@yahoo.com). owing to cost and design considerations, the existing $270 \mathrm{kV}$ transmission towers (L12 type) are to be used for this upgrading purpose. The upgraded system voltage is used to match the to-be-developed $400 \mathrm{kV}$ connection between countries North Africa.

In this project, the effects of wind on the tower top geometry are studied. In particular, it aims to determine whether the L12 towers are suitable for the upgrading purpose of the area with the same weather condition.

\section{MODEL DEVELOPMENT}

In this section, details of the modelling work and the techniques involved are described. Development of several required models is also presented.

\section{A. Transmission Line Components}

Overhead power lines consist mainly of three parts: tower; conductor; and insulator. The structure (Tower) for overhead lines can have a variety of shapes depending on the type of line. An aluminium alloy conductor (AAAC) is used primarily for medium and high voltage lines. In this study, $400 \mathrm{kV}$ is going to be used with a L12 tower so the suitable conductor from Table $\mathrm{I}$ is $2 \times 700 \mathrm{~mm}^{2}$ AAAC (Araucaria $\times 1$ ).

TABLE I: CONDUCTOR TyPE AND SIZE SELECTION BASED ON NOMINAL VOLTAGES [5].

\begin{tabular}{|c|c|c|c|}
\hline Tower Design & $\begin{array}{c}\text { Bundle } \\
\text { Designation }\end{array}$ & Conductor System & $\begin{array}{l}\text { Nominal Rated } \\
\text { Temperature }\left({ }^{\circ} \mathrm{C}\right)\end{array}$ \\
\hline $\begin{array}{c}\mathrm{L} 4 \\
132 \mathrm{kV}\end{array}$ & L4 (M) & $1 \times 175 \mathrm{~mm}^{2} \mathrm{ACSR}$ & 50 \\
\hline $\begin{array}{c}\mathrm{L7} \\
132 \mathrm{kV}\end{array}$ & L7 (C) & $2 \times 175 \mathrm{~mm}^{2} \mathrm{ACSR}$ & 50 \\
\hline \multirow{2}{*}{$\begin{array}{c}\mathrm{L} 3 \\
275 \mathrm{kV}\end{array}$} & $\mathrm{L} 3 / 1$ & $1 \times 700 \mathrm{~mm}^{2}$ AAAC & 50 \\
\hline & $L 3 / 2^{\star}$ & $2 \times 300 \mathrm{~mm}^{2}$ AAAC & 50 \\
\hline \multirow{2}{*}{$\begin{array}{c}\text { L66 } \\
275 \mathrm{kV}\end{array}$} & L66/1 & $1 \times 700 \mathrm{~mm}^{2}$ AAAC & 50 \\
\hline & $\angle 66 / 2^{*}$ & $2 \times 300 \mathrm{~mm}^{2}$ AAAC & 50 \\
\hline \multirow{3}{*}{$\begin{array}{c}\mathrm{L} 2 \\
400 \mathrm{kV}\end{array}$} & $L 2 / 2$ & $2 \times 500 \mathrm{~mm}^{2} \mathrm{AAAC}$ & 75 \\
\hline & L2/6 & $2 \times 620 \mathrm{~mm}^{2}$ GZTACSR & 170 \\
\hline & $L 2 / 4^{*}$ & $2 \times 570 \mathrm{~mm}^{2} \mathrm{AAAC}$ & 75 \\
\hline \multirow{3}{*}{$\begin{array}{c}\mathrm{L8} \\
400 \mathrm{kV}\end{array}$} & $\mathrm{L} 8 / 2$ & $2 \times 500 \mathrm{~mm}^{2}$ AAAC & 75 \\
\hline & L8/6 & $2 \times 620 \mathrm{~mm}^{2}$ GZTACSR & 170 \\
\hline & $L 8 / 4^{*}$ & $2 \times 570 \mathrm{~mm}^{2} \mathrm{AAAC}$ & 75 \\
\hline \multirow{4}{*}{$\begin{array}{c}\mathrm{L} 6 \\
400 \mathrm{kV}\end{array}$} & L6/2 & $2 \times 700 \mathrm{~mm}^{2} \mathrm{AAAC}$ & 75 \\
\hline & L6/3 & $2 \times 500 \mathrm{~mm}^{2} \mathrm{AAAC}$ & 75 \\
\hline & $L 6 / 4$ & $2 \times 850 \mathrm{~mm}^{2}$ AAAC & 75 \\
\hline & L6/5 & $3 \times 700 \mathrm{~mm}^{2}$ AAAC & 50 \\
\hline \multirow{2}{*}{$\begin{array}{c}\mathrm{L} 12 \\
400 \mathrm{kV}\end{array}$} & L12 & $2 \times 700 \mathrm{~mm}^{2} \mathrm{AAAC}$ & 75 \\
\hline & $\mathrm{L} 12 / 1$ & $2 \times 850 \mathrm{~mm}^{2} \mathrm{AAAC}$ & 75 \\
\hline
\end{tabular}

Insulators must hold and support the conductors, and withstand both the normal operating voltage and surges owing to switching and lightning. The minimum creepage length and the length of the insulator string is as specified in Table II. There is no tolerance permitted on minimum creepage length of the insulator string. The overall length of the insulator string is measured from the bottom of the ball of the last 
insulator to the bottom of an imaginary ball, fitted into the socket of the first insulator. In the case of a composite unit, the length is measured from the bottom of the ball to the bottom of an imaginary ball, fitted into the socket end fitting.

TABLE II: OVERHEAD LINE 400 KV INSULATOR STRING [6]

\begin{tabular}{|l|c|c|}
\hline & $\begin{array}{c}\text { Minimum creepage } \\
\text { length }(\mathrm{mm})\end{array}$ & $\begin{array}{c}\text { Insulator string } \\
\text { length }(\mathrm{mm}) \pm 2 \%\end{array}$ \\
\hline Tension & 9000 & 4200 \\
\hline Suspension & 12500 & 4100 \\
\hline
\end{tabular}

\section{B. Loadings Applied To Transmission Line Components}

Wind load is one of the important factors that should be taken into consideration when designing reliable overhead transmission lines. The displacement of live conductors and insulators towards the tower body will shorten the clearances, increasing the risk of electrical flashover, while movement away from the tower body may cause an infringement of the shielding angle coverage, and expose lines to a direct lightning strike. The wind direction has a high impact on the clearances infringement. Wind perpendicular to the conductors has the greatest impact to move the conductors in tower direction and induce maximum swing angle. As shown in Fig. 1.

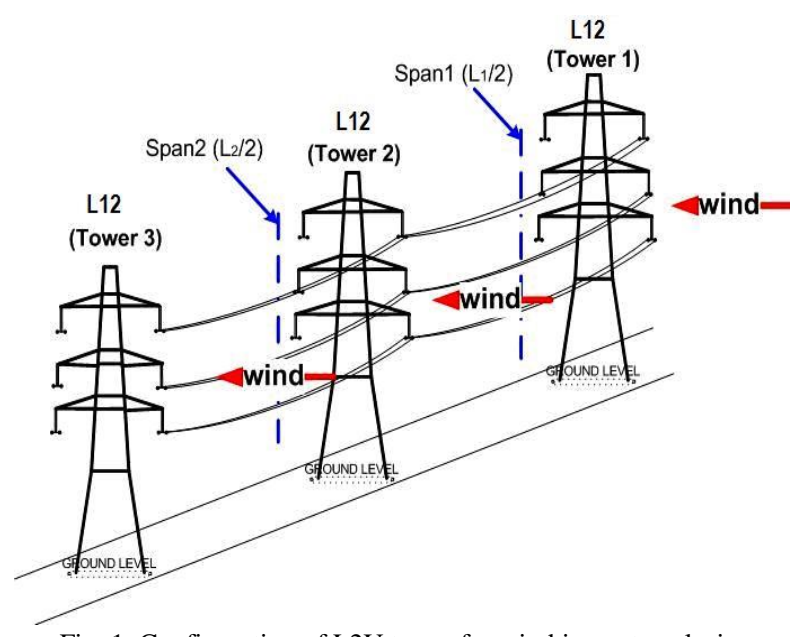

Fig. 1. Configuration of L2U tower for wind impact analysis.

\section{Wind Loads on Conductors and Insulators}

Winds that hit the connectors can be considered as mechanical loads, these loads known as the wind pressure load $\left(A_{c}\right)$. Wind pressure is directly proportional to the mechanical tensile. Due to the effect of wind on the span length $\mathrm{L}$, the loads resulting from the wind can be calculated from the equation (1).

$$
A_{c}=C_{c} \times d_{c r} \times K \times \frac{L_{1}+L_{2}}{2} \times \sin ^{2} \Omega \quad m^{2}
$$

In the above equation, $C_{c}$ is the drag coefficient factor, $d_{c r}$ is the conductor diameter in meters, and $k$ is the span correction factor. $L_{1}$ and $L_{2}$ are the spans of a line erected on three towers, shown in Fig. 3 below. $\Omega$ is the wind direction angle in degrees, with respect to the span line (also shown in Fig. 3).

Wind loads acting on insulator sets come from the load Ac transferred by the conductors, and from the wind pressure acting directly on the insulators. The latter load is applied conventionally at the attachment point to the tower in the direction of the wind, and its intensity is given by:

$$
A_{c}=a_{i} \times G_{i} \quad m^{2}
$$

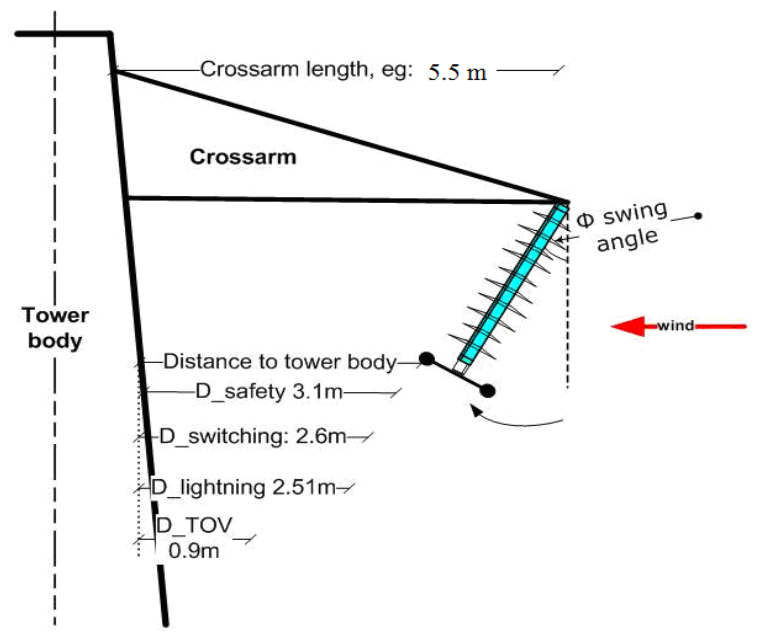

Fig. 2. Swing angle and related required clearances for $400 \mathrm{kV}$ system voltage.

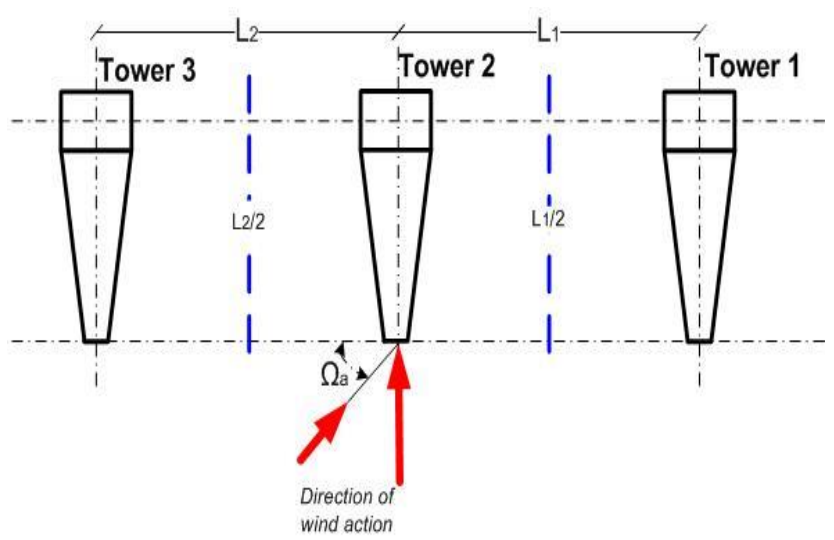

Fig. 3. Illustration method in determining the wind loading on conductor.

The total wind loading area of the insulators is determined by multiplying the total area seen in side view, $a_{i}$, by the drag factor, $G_{i}$, as shown in equation 2 .

\section{Swing of Conductors}

High wind velocity can cause significant problems for transmission lines. In many countries, most of the overhead transmission lines cross desert and open areas, and some are located at high altitude. For these reasons, the overhead power line tower structure is exposed to the effect of weather, such as strong wind (in fact, the wind speed increases when the altitude increases). This amount of wind speed force the conductor to move in fluctuation shape so the electrical clearances will change depending on the speed velocity. If the wind stays for a long time, the conductors will transfer the movement to the insulators' support, as shown in Fig. 4, where the movement of the insulator caused the swing angle movement to the insulators' support, as shown in Fig. 4, where the movement of the insulator caused the swing angle.

This movement of live conductors and insulators towards the tower structure will shorten the clearances between the conductors and tower, which increases the risk of electrical flashover. 


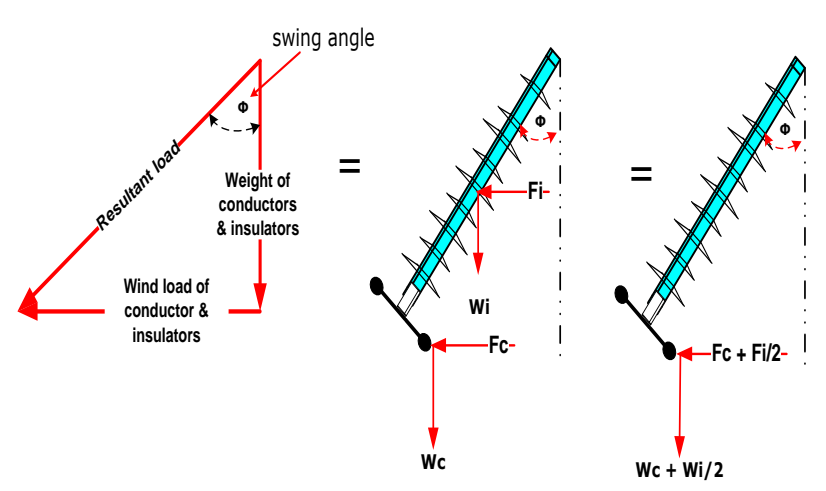

Fig. 4. Determination of swing angle on the basis of relative horizontal (wind) and vertical (system weight) forces.

When designing the tower top geometry, the distance between the live conductors and the nearest earthed structure should exceed the safety clearance value in still air and light wind. In many Europe countries, a swing angle up to $10^{\circ}$ should not lead to any infringement of any stated clearance. In very high winds that cause a large swing angle $\left(35^{\circ}\right.$ based on the data in [4]), the infringement will happen, and the clearances will only withstand the power frequency voltage which is required in this case. probability to have lightning and high wind speed at the same time very rare.

The methods for calculating the reposition of conductors and insulators towards an overhead line tower due to the wind speed created by the CIGRE Working Group [4]. Also some changes made to adapt the condition of high wind speed. The swing angle of an overhead line conductor and insulator is determined by the formula given in equation 3 .

$$
\phi=\tan ^{-1}\left[\frac{q_{z} \times\left(A_{c}+\frac{A_{i}}{2}\right)}{W_{c}+\frac{W_{i}}{2}}\right]
$$

In equation $3, q_{z}$ is the dynamic wind pressure, $A_{c}$ is the wind loading area of the conductor, $A_{i}$ is the wind loading area of the insulators, $W_{c}$ is the total weight of the conductors, and $W_{i}$ is the total weight of the insulators. The equation effectively derives the swing angle on the basis of relative horizontal (wind) and vertical (system weight) forces. To determine the dynamic wind pressure, $q_{z}$, that is used in equation 3 , it is important to understand the wind speed distributions used to calculate this value.

Reference wind speeds, VR, are presented in standards [6]. VR can be used to calculate the maximum average 10-minute wind speed, VT, which will occur in a given return period. For a return period that is equal to or greater than two years, the modified version of Gumbel's formula [6] can be used. This is shown below as equation 4 .

$$
\overline{V_{T}} \geq 2 \text { year }=\overline{V_{R}}-\sigma_{V_{R}}\left[0.45+\ln \left(-\ln \left(1-\frac{1}{T}\right)\right) \times \frac{\sqrt{6}}{\pi}\right]
$$

Accounting for the roughness of terrain and the height of the considered conductor. $V_{z}$, the average value of wind velocity occurring at a specified height above the site ground level, $\mathrm{z}$, is obtained from the formulae defined in equations 5 and 6 , for open terrain with few obstacles.

$$
\begin{aligned}
& \overline{V_{Z}}=\overline{V_{T}} \times\left(\frac{z-h_{e}}{10}\right)^{\alpha} \text { for } z \geq 10+h_{e} \mathrm{~m} \cdot \mathrm{s}^{-1} \\
& \overline{V_{Z}}=\frac{\bar{V}}{2} \times\left(1+\frac{z}{10+h_{e}}\right)^{\alpha} \text { for } z \geq 10+h_{e} \mathrm{~m} \cdot \mathrm{s}^{-1}
\end{aligned}
$$

Using the value $V_{z}$, the dynamic wind pressure, $q_{z}$, can be calculated as shown in equation 7 below. The air density, $\rho$, depends on the temperature and the altitude of the line above sea level [7], [8]. In general, $\rho$ may be taken as $1.22 \mathrm{~kg} . \mathrm{m}^{-3}$, based on a temperature measurement of $+20^{\circ} \mathrm{C}$ and a height of $0 \mathrm{~m}$ above sea level.

$$
q_{z}=\frac{\rho}{2} \times \bar{V}_{z}^{2}
$$

\section{E. Conventional L12 Tower}

The L12 tower is a new model for delivering energy at 400 $\mathrm{kV}$. A twin bundle of $700 \mathrm{~mm}^{2}$ AAAC is preferred for use. The tower is designed to ensure sufficient electrical clearances. The ratio of creepage distance to insulator length used in this case is 3.05 [8]. This ratio is obtained by dividing the required $12.5 \mathrm{~m}$ creepage distance by the insulator length $4.1 \mathrm{~m}$, as shown in Fig. 5, which illustrates the main dimensions of a typical L12 tower. The study is based on towers carrying twin conductor bundles (separated at $0.5 \mathrm{~m}$ by horizontal spacers) of AAAC Araucaria conductors, of $0.03726 \mathrm{~m}$ diameter and total weight of $18.5 \mathrm{kN}$, based on manufacturer's data of $0.023 \mathrm{kN} / \mathrm{m}$ for $400 \mathrm{~m}$ span. This span value is for a L12 tower [9], [10] and is the metric equivalent of $1,312 \mathrm{ft}$. The insulator is taken to be equipped with fittings with a total length of $0.5 \mathrm{~m}$, giving a total string length of 4.6 $\mathrm{m}$. The insulator used in this case study is taken to have a wind loading area $0.8 \mathrm{~m}^{2}$, and a drag factor 0.12 , according to the data in [7], [11]-[13].

The L12 tower is a new model for delivering energy at 400 $\mathrm{kV}$. A twin bundle of $700 \mathrm{~mm}^{2}$ AAAC is preferred for use. The tower is designed to ensure sufficient electrical clearances. The ratio of creepage distance to insulator length used in this case is 3.05 [8]. This ratio is obtained by dividing the required $12.5 \mathrm{~m}$ creepage distance by the insulator length $4.1 \mathrm{~m}$, as shown in Fig. 5, which illustrates the main dimensions of a typical L12 tower. The study is based on towers carrying twin conductor bundles (separated at $0.5 \mathrm{~m}$ by horizontal spacers) of AAAC Araucaria conductors, of $0.03726 \mathrm{~m}$ diameter and total weight of $18.5 \mathrm{kN}$, based on manufacturer's data of $0.023 \mathrm{kN} / \mathrm{m}$ for $400 \mathrm{~m}$ span. This span value is for a L12 tower [9], [10] and is the metric equivalent of 1,312 ft. The insulator is taken to be equipped with fittings with a total length of $0.5 \mathrm{~m}$, giving a total string length of 4.6 $\mathrm{m}$. The insulator used in this case study is taken to have a wind 
loading area $0.8 \mathrm{~m}^{2}$, and a drag factor 0.12 , according to the data in [7], [11]-[13].

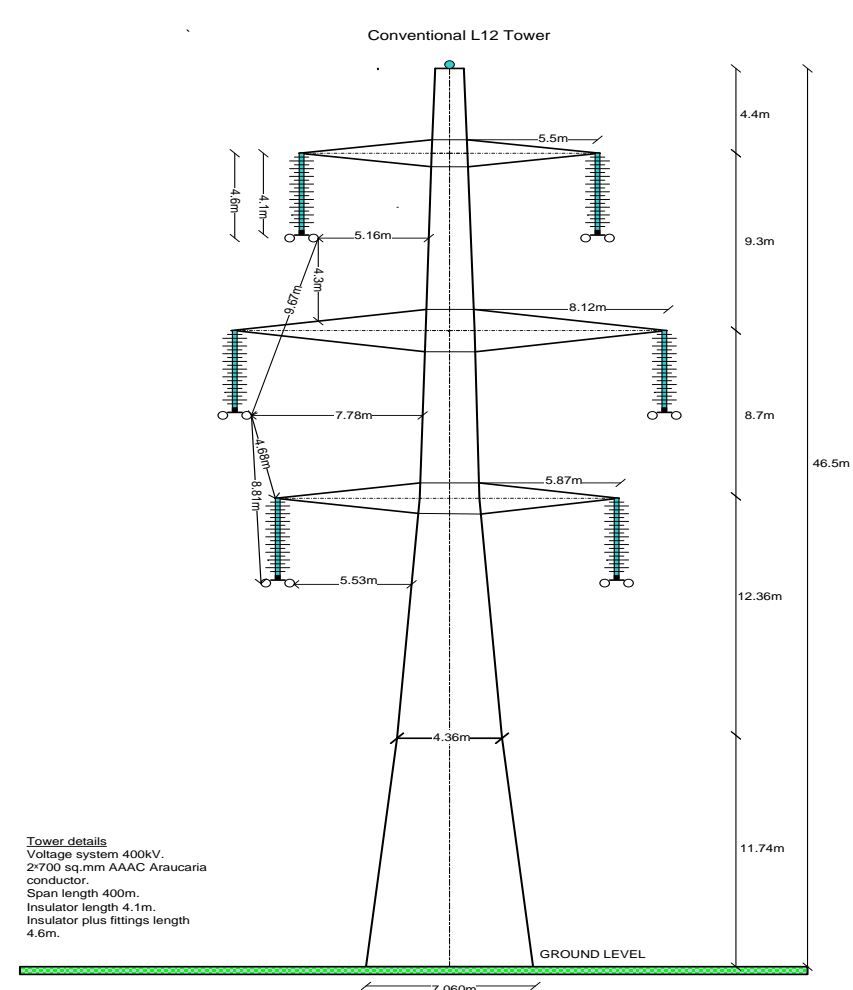

Fig. 5. Dimensional details of 400kV L12 tower.

On the basis of the insulator and the height of the lower cross-arm, the $7.6 \mathrm{~m}$ minimum clearance to ground [12], [14], [15] will be infringed only when the sag exceeds $12 \mathrm{~m}$. This value of sag is therefore used as reference. The normal sag for $400 \mathrm{~m}$ span is $5.4 \mathrm{~m}$. In this case the distance between the conductor and ground is $14.5 \mathrm{~m}$, which is greater than $7.6 \mathrm{~m}$; the minimum clearance to the ground.

\section{F. Derivation of Equations to Calculate Distance Infringement}

When the insulator moves owing to the wind action, the distance between the conductor and tower body infringes either to increase or decrease. The distance infringement will vary from one cross-arm to another, depending on the cross-arm length and its height from ground level. To calculate the distance infringement, some analysis should be taken into consideration on the tower, as shown in Fig. 6. Then, some equations have to find the horizontal and vertical distances between the conductors and any part of the tower body.

It is necessary to name all the tower parts and the possible positions to drive accurate equations. For example: $\mathrm{CC}^{\prime}$ is the cross-arm length, $\mathrm{AB}$ the insulator length and $\mathrm{NK}$ is the possible distance between the conductor and tower body etc. Then, the equations can be found based on these tower parts (Fig. 6), names as shown in the equations (8 to 10) below.

$$
\begin{aligned}
& k n=\left[c c^{\prime}\right]-\left[\begin{array}{l}
\left\{\left(a b+c e^{\prime}\right)-|\sin (\alpha) \times(2 \times a b \times \sin (\phi / 2))|\right\} \\
\times\left\{\frac{\tan (\theta) \times c e^{\prime}}{c^{\prime} a / 2}\right\}
\end{array}\right]-(8) \\
& {[|\cos (\alpha) \times(2 \times a b \times \sin (\phi / 2))|]-[\text { condbundle } / 2]}
\end{aligned}
$$

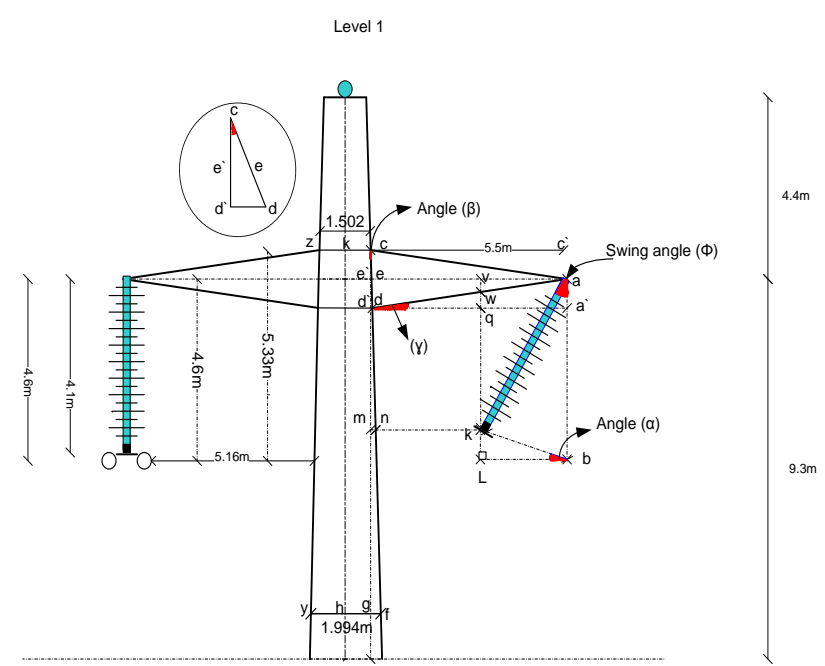

Fig. 6. Analysis of 400kV L12 tower.

$k n$, is the horizontal distance between the conductor tower body at any swing angle possible. $k w$, presents the vertical distance between the conductor and top cross-arm based on swing angle and conductor movement.

$$
\begin{aligned}
& k w=[a b]-\left[\begin{array}{l}
a a^{\prime}-\sin (\gamma) \times \\
\frac{\left(c c^{\prime}-\tan (\theta) \times c^{\prime} a \times 2\right)-|\cos (\alpha) \times 2 \times a b \times \sin (\phi / 2)|}{\cos (\gamma)}
\end{array}\right] \text { (9) } \\
& +|\sin (\alpha) \times(2 \times a b \times \sin (\phi / 2))|
\end{aligned}
$$

$k w_{2}$ ' presents the vertical distance between the conductor and bottom cross-arm based on swing angle and conductor movement.

$$
\begin{aligned}
& k w_{2}^{\prime}=[|\sin (\alpha) \times 2 \times a b \times \sin (\phi / 2)|]+ \\
& {\left[b a_{2}-\frac{\left(c_{2}^{\prime} a_{2} \times\left(c c^{\prime}-g f\right)\right)}{c_{2}^{\prime} c_{2}}\right]+} \\
& {\left[c_{2}^{\prime} a_{2} \times \frac{\left(c c^{\prime}-g f\right)-(|\cos (\alpha) \times 2 \times a b \times \sin (\phi / 2)|)}{c_{2}^{\prime} c_{2}}\right]}
\end{aligned}
$$

As a matter of fact, equations (8) and (9), mentioned above, can be used for all top, middle and bottom cross-arms. Equation 10 can be used for the top and middle cross-arms, and it has to be modified for use in the bottom cross-arm, because there is no impediment under the bottom cross-arm and it is subjected directly to the ground.

$$
k_{3} g_{3}=b_{3} g_{3}+\left|\sin (\alpha) \times 2 \times a_{3} b_{3} \times \sin (\phi / 2)\right|
$$

$k_{3} g_{3}$ is the vertical distance between the conductor in lower cross-arm and the ground level based on swing angle and the conductor movement.

\section{G. Calculation of Clearances for Fast Front, Slow Front, and PF over Voltages}

In 'still air' the clearances have to be wide enough to withstand lightning and switching impulses. The lightning impulse used is that which can propagate beyond a few towers from the point of the lightning strike. For the purpose of determining clearances this is taken as U50FF, the mean 
lightning impulse voltage which results in $50 \%$ flashover and $50 \%$ withstands of gap formed between the live parts and the tower. The switching impulse used is the highest that can occur on the lines called UmaxSF. There are ways of limiting the switching surges, such as line entry surge arresters or pre-insertion resistors, in which case the appropriate UmaxSF is the maximum value which can occur on the transmission lines. The corresponding distance for lightning LFF and LSF, are calculated using the formulae below, which are based on IEC60071.

$$
\begin{gathered}
L_{F F}=\frac{U 50_{f f o}}{530 \times\left(0.74+0.26 \times K_{g}\right) \times K_{A}} \\
L_{S F}=\frac{e^{\left(\frac{U 50_{s f o}}{1080 \times K_{g} \times K_{A}}\right)}-1}{0.46} \\
L_{P F}=\left(\frac{e^{\left(\frac{U 50_{p f}}{750 \times \sqrt{2} \times K_{g} \times K_{A}}\right)}-1}{0.55}\right)^{0.833}
\end{gathered}
$$

\section{RESUlts AND ANALYSIS RESUlts}

Since 1970, $270 \mathrm{kV}$ overhead transmission lines have been used in Libya to supply electricity to Benghazi City (northern part of the country). Nowadays, owing to the increase in population, a $400 \mathrm{kV}$ system will be used instead of $275 \mathrm{kV}$ in the near future. In the case of $400 \mathrm{kV}$, twin bundles of 500 $\mathrm{mm} 2$ or $700 \mathrm{~mm} 2$ AAAC type conductor are preferred, and $4.6 \mathrm{~m}$ insulator length [15]. According to GECOL design standard, $V R=35 \mathrm{~m} . \mathrm{s}-1$ [2].

Apply in equations 1 to 7 to calculate the swing angle at this amount of wind speed $35 \mathrm{~m} . \mathrm{s}-1$ and the result as shows in table 3.

TABLE III: OVERHEAD LINE 400 KV INSULATOR STRING [6]

\begin{tabular}{|l|l|l|l|l|}
\hline$V_{T}$ & $V_{Z}$ & $q_{z}$ & $A_{C}$ & $\boldsymbol{\phi}_{\max }$ \\
\hline 34.78 & 38.86 & 921 & 11.9 & 31 \\
\hline $\mathrm{m} . \mathrm{s}^{-1}$ & $\mathrm{~m} . \mathrm{s}^{-1}$ & & $\mathrm{~m}^{2}$ & $\mathrm{deg}$ \\
\hline
\end{tabular}

The clearances have to be wide enough to withstand lightning and switching impulses. These clearances are calculated according to equations $3.15,3.16$ and 3.17 , based on IEC 60071-1 (1993), and find the conductor distance to tower body to withstand lightning U50, switching U50 and TOV. After applying the equations, the clearance is found as follows: $\mathrm{LFF}=2.51 \mathrm{~m}, \mathrm{LSF}=2.6 \mathrm{~m}$ and $\mathrm{LPF}=0.9 \mathrm{~m}$.

Fig. 7 shows the relation of the swing angle and the distance between the top cross-arm conductor and the tower body (horizontal), as well as the cross-arm above (vertical) and the cross-arm below (vertical) for the base design. In the first and second cases, the swing angle increases as the clearances decrease. In the third case the swing angle increases as the clearance also increases. The impact is most significant on the horizontal clearances side (first case), as the infringement of the safety and transient clearances can occur for a $27^{\circ}$ swing angle. In contrast, a large swing angle $\left(\geq 40^{\circ}\right)$ is needed for vertical clearance between the conductor and the cross-arm above to infringe these clearances. This value is above the maximum limit of $35^{\circ}$ defined in [4], so the chance of the conductor position infringing the safety clearance is zero. In addition, the third case chance of infringing the safety and electrical clearance is also zero.

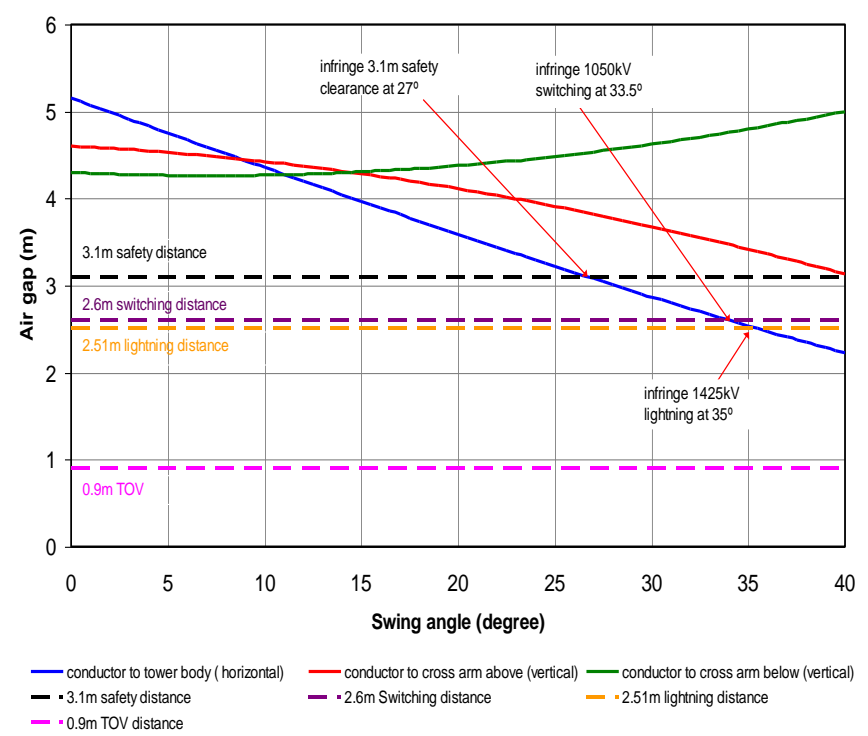

Fig. 7. Relationship of the swing angle with the distance from tower to the top cross-arm conductor for 400kV L12 tower.

Fig. 8 shows the relation of the swing angle and the distance between the top cross-arm conductor and the tower body (horizontal), cross- arm above (vertical) and cross-arm below (vertical) for the base design. In the first and second cases, the swing angle increases as the clearances decreases. In the third case, the swing angle increases as the clearance increases as well.

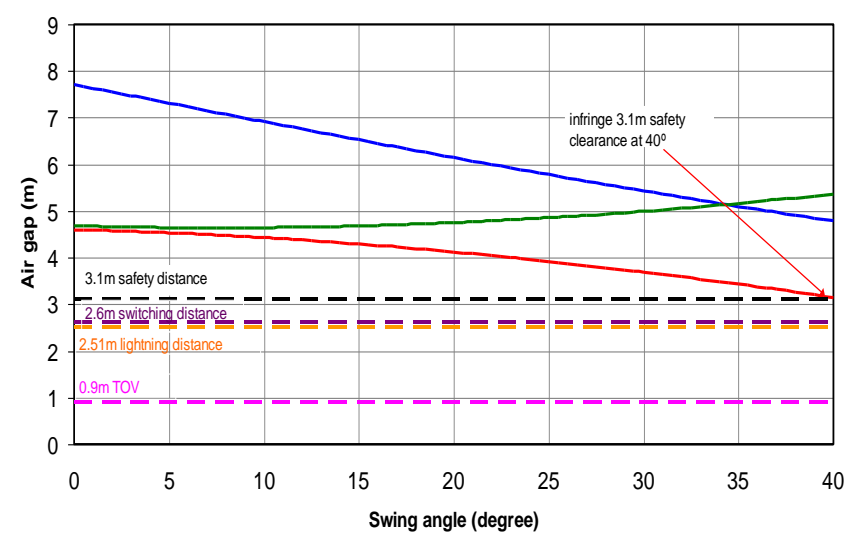

— conductor to tower body ( horizontal) —conductor to cross arm above (vertical) —conductor to cross arm below (vertical)

Fig. 8. Relationship of swing angle with the distance from tower to the middle cross-arm conductor for $400 \mathrm{kV}$ L12 tower.

The impact is most significant on the vertical clearances side (second case), as the infringement of the safety and transient clearances can occur for a $40^{\circ}$ swing angle. In first (horizontal) and third (vertical to lower cross-arm) cases, the likelihood of the conductor position infringing the safety and 
electrical clearances is zero, because the middle cross-arm is long, as shown in Fig. 5 (middle cross-arm 8.12m length).

Fig. 9 shows the relation of the swing angle and the distance between the top cross-arm conductor and the tower body (horizontal), and the cross-arm above (vertical) and cross-arm below (vertical) for the base design. In the first and second cases, the swing angle increases as the clearances decreases. The third case here is different because there is no cross-arm below the Lower cross-arm (as shown in Fig. 3 and 4), and the Lower cross-arm is subjected to the ground, and the distance to the ground is almost $20 \mathrm{~m}$.

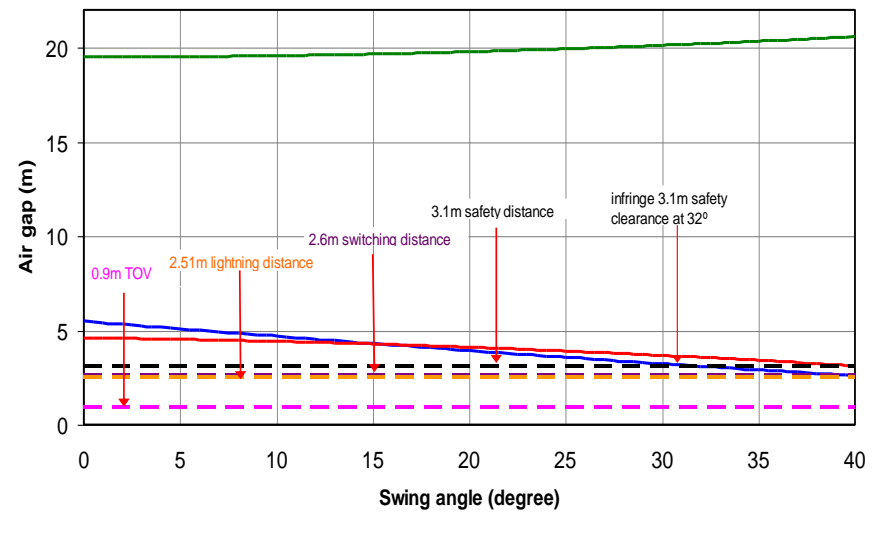

- conductor to tower body ( horizontal) $\quad$ - conductor to cross arm above (vertical) $\quad$ - conductor to ground(vertical) Fig. 9. Relationship of swing angle with the distance from tower to the Lower cross-arm conductor for $400 \mathrm{kV} \mathrm{L1} 2$ tower.

The impact is most significant on the horizontal clearances side (first case), as the infringement of the safety and transient clearances can occur for a $32^{\circ}$ swing angle. The chance of clearance infringing the vertical distance between the conductor in lower cross-arm and cross-arm above is zero, because more than $35^{\circ}$ is needed to make this clearance infringement.

High wind speeds drive the conductor to move closer to the tower body. The displacement of live conductors and insulators towards the tower body will shorten the clearances, as shown in Fig. 10; the relationship between wind speed and conductor distance to tower body.

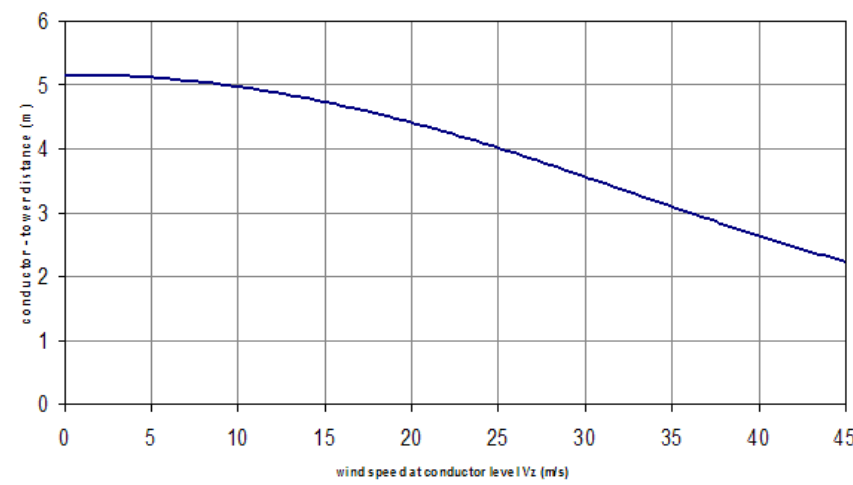

Fig. 10. Horizontal clearance between conductor and tower body as a function of wind speed of 400kV L12 tower.

High wind speeds also drive the conductor to move up towards the upper cross-arm and away from the ground. Even if the change is not much, it is still considered as much the wind speed increase as the height of the conductor increase as shown in Fig. 11. When the conductor IS exposed to light or average wind the conductor height does not change much, from $V_{Z}=0$ to $V_{Z}=20 \mathrm{~ms}^{-1}$ The change in conductor height is less than $0.07 \mathrm{~m}$, but if the conductor is stroked by high or extremely high wind speeds the change in conductor height will be remarkable, from $V_{Z}=20$ to $V_{Z}=45 \mathrm{~ms}^{-1}$ the change in conductor height exceed to reach $1 \mathrm{~m}$.

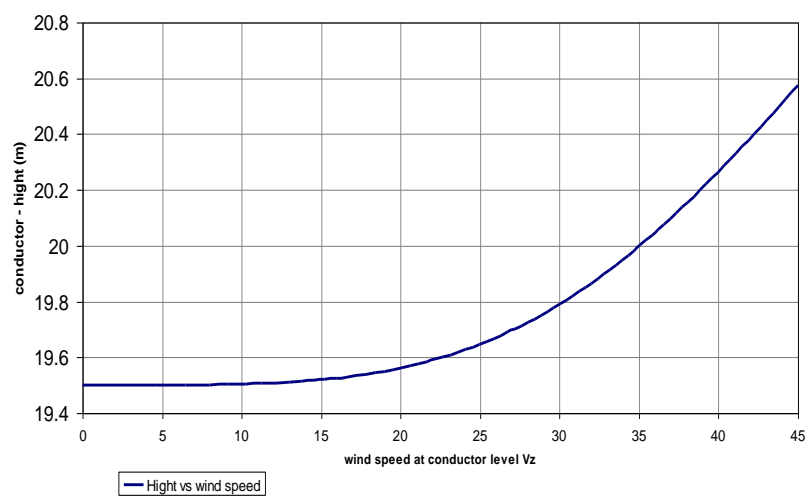

Fig. 11. Relationship between the conductor height from the ground and wind speed of $400 \mathrm{kV}$ L12 tower.

In still air the clearances have to be wide enough to withstand lightning and switching impulses. The probability of having maximum wind speed and a lightning strike at the same time is very low, so it can be ignored. Therefore, the graph in Fig. 7 can be plotted in terms of the relationship between the tower and the nearest conductor. This is shown in Fig. 12 below. The required withstand levels are also shown in the graph.

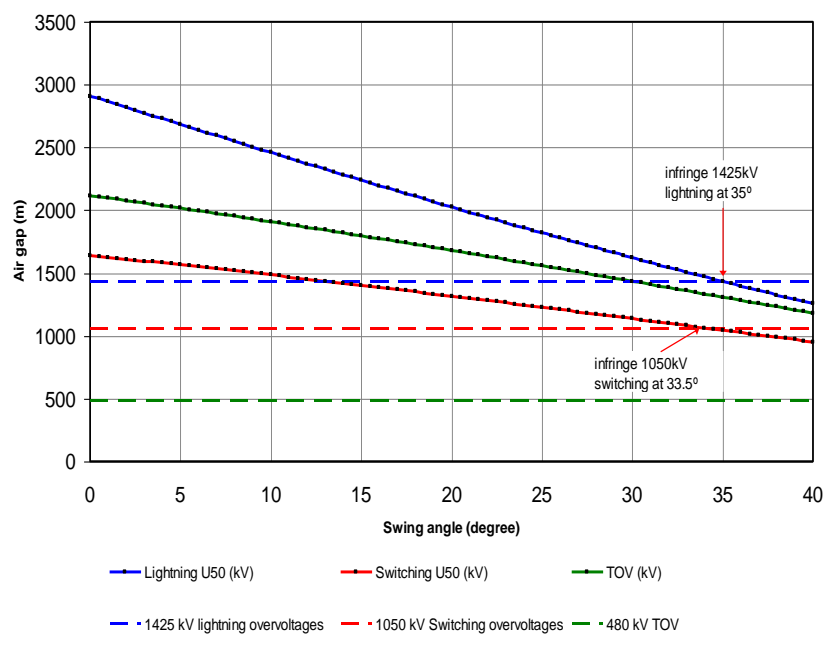

Fig. 12. Relationship of the swing angle with U50 overvoltage levels of the base case $400 \mathrm{kV}$ L12 tower.

The data plotted in these graphs from Fig. 6 to Fig. 12 can be used to calculate the annual frequency at which the swing angle will be such that a particular clearance will be infringed. In this base case, a wind speed value of $34 \mathrm{~m} / \mathrm{s}$, as described above, will move the conductors and the insulators through an angle of $26.5^{\circ}$, causing them to infringe the $3.1 \mathrm{~m}$ safety distance. This corresponds to a return period of 0.0034 years, or once every 1.25 days. Statistically, the line may therefore see an infringement of the safety clearance roughly 292 times per year.

In the same way, a wind speed of $40 \mathrm{~m} / \mathrm{s}$ will put the tower 
at risk of flashover during conditions where switching surges occur. This will happen with a return period of 0.013 years, or once every 4.6 days ( 79 times per year). A similar means is used to find lightning impulses; $41 \mathrm{~m} / \mathrm{s}$ makes the tower a lightning hazard during conditions where lightning occurs. This will happen in return period of 0.014 years or once every 5.1 days (71 times per year). It is extremely unlikely that the temporary overvoltage clearance will ever be exceeded; the wind speeds required for a $70^{\circ}$ swing are likely to have caused other mechanical damage to the tower. All of this information is summarised in Table IV to Table VI.

TABLE IV: PROBABILITY OF INFRINGEMENT OF HORIZONTAL CLEARANCES OWING TO CONDUCTOR SWING FOR BASE CASE TOWER DESIGN FOR TOP

\begin{tabular}{|c|c|c|c|c|}
\hline L2U Tower & $\begin{array}{c}\text { Safety } \\
\text { Distance } \\
(3.1 \mathrm{~m})\end{array}$ & $\begin{array}{c}1050 \mathrm{kV} \\
\text { Switching } \\
\text { Overvoltage } \\
\text { Level }(2.6 \mathrm{~m})\end{array}$ & $\begin{array}{c}1425 \mathrm{kV} \\
\text { Lightning } \\
\text { Overvoltage } \\
\text { Level }(2.51 \mathrm{~m})\end{array}$ & $\begin{array}{c}480 \mathrm{kV} \text { TOV } \\
\text { Level }(0.9 \mathrm{~m})\end{array}$ \\
\hline $\begin{array}{c}\text { Swing Angle to Infringe } \\
\Phi\left({ }^{\circ}\right)\end{array}$ & 26.50 & 34 & 35 & 70 \\
\hline $\begin{array}{c}\text { Required Wind Velocity at } \\
\text { Conductor Level } \\
\left.\text { Vz (ms }{ }^{-1}\right)\end{array}$ & 34 & 40 & 41 & 81 \\
\hline $\begin{array}{c}\text { Retum Period } \\
\mathrm{T} \text { (Years) }\end{array}$ & 0.0034 & 0.013 & 0.014 & 3143 \\
\hline $\begin{array}{c}\text { Retum Period } \\
\mathrm{T} \text { (Days) }\end{array}$ & 1.25 & 4.6 & 5.1 & 1131775 \\
\hline Infringements / Year & 292 & 79 & 71 & $0.000322 \approx 0$ \\
\hline
\end{tabular}

TABLE V: PROBABILITY OF INFRINGEMENT OF VERTICAL CLEARANCES BETWEEN CONDUCTOR AND CROSS-ARM OWING TO CONDUCTOR SWING FOR 400KV L12 TOWER FOR TOP CROSS-ARM

\begin{tabular}{|c|c|c|c|c|}
\hline L2U Tower & $\begin{array}{c}\text { Safety } \\
\text { Distance } \\
(3.1 \mathrm{~m})\end{array}$ & $\begin{array}{c}1050 \mathrm{kV} \\
\text { Switching } \\
\text { Overvoltage } \\
\text { Level (2.6m) }\end{array}$ & $\begin{array}{c}1425 \mathrm{kV} \\
\text { Lightning } \\
\text { Overvoltage } \\
\text { Level (2.51m) }\end{array}$ & $\begin{array}{c}480 \mathrm{kV} \text { TOV } \\
\text { Level (0.9m) }\end{array}$ \\
\hline $\begin{array}{c}\text { Swing Angle To } \\
\text { Infringe } \\
\left.\Phi()^{\circ}\right)\end{array}$ & 40.5 & 49 & 50 & 71 \\
\hline $\begin{array}{c}\text { Required Wind } \\
\text { Velocity At Conductor } \\
\text { Level } \\
\text { Vz (m/s) }\end{array}$ & 45.5 & 52 & 54 & 83 \\
\hline $\begin{array}{c}\text { Retum Period } \\
\mathrm{T} \text { (Years) }\end{array}$ & 0.05 & 0.46 & 0.72 & 6346 \\
\hline $\begin{array}{c}\text { Retur Period } \\
\mathrm{T} \text { (Days) }\end{array}$ & 18.18 & 168 & 261 & $22 \mathrm{E} 6$ \\
\hline Infringements / Year & 20 & 2 & 1.3 & $1.6 \mathrm{E}-6$ \\
\hline
\end{tabular}

TABLE VI: PROBABILITY OF INFRINGEMENT OF VERTICAL CLEARANCES BETWEEN CONDUCTOR AND CROSS-ARM BELOW OWING TO CONDUCTOR SWING FOR BASE CASE TOWER FOR TOP CROSS-ARM

\begin{tabular}{|c|c|c|c|c|}
\hline L2U Tower & $\begin{array}{c}\text { Safety } \\
\text { Distance } \\
(3.1 \mathrm{~m})\end{array}$ & $\begin{array}{c}1050 \mathrm{kV} \\
\text { Switching } \\
\text { Overvoltage } \\
\text { Level }(2.6 \mathrm{~m})\end{array}$ & $\begin{array}{c}1425 \mathrm{kV} \\
\text { Lightning } \\
\text { Overvoltage } \\
\text { Level }(2.51 \mathrm{~m})\end{array}$ & $\begin{array}{c}\text { 480kV TOV } \\
\text { Level (0.9m) }\end{array}$ \\
\hline $\begin{array}{c}\text { Swing Angle To } \\
\text { Infringe } \\
\Phi\left(^{\circ}\right)\end{array}$ & $\infty$ & $\infty$ & $\infty$ & $\infty$ \\
\hline $\begin{array}{c}\text { Required Wind } \\
\text { Velocity At Conductor } \\
\text { Level } \\
\text { Vz (m/s) }\end{array}$ & $\infty$ & $\infty$ & $\infty$ & $\infty$ \\
\hline $\begin{array}{c}\text { Return Period } \\
\text { T (Years) }\end{array}$ & $\infty$ & $\infty$ & $\infty$ & $\infty$ \\
\hline $\begin{array}{c}\text { Retum Period } \\
\text { T (Days) }\end{array}$ & $\infty$ & $\infty$ & $\infty$ & $\infty$ \\
\hline Infringements / Year & 0 & 0 & 0 & $\infty$ \\
\hline
\end{tabular}

\section{CONCLUSION}

Only wind direction perpendicular to the line causes maximum swing angles. Since very often only the time distribution of wind velocities is known, without reference to the wind direction, the time probability of swing angles has to be determined by approximation. In this paper, some methods and approaches have been found to calculate the swing angle $\Phi$, for $400 \mathrm{kV}$ lines located in Northern Libya. The wind time distribution has also been calculated in this paper. In still air, or under very moderate winds, the clearances should be wide enough to withstand lightning or switching impulse voltages, and in under high wind the clearances may be related to power frequency voltage.

The clearances necessary to withstand The $400 \mathrm{kV}$ line in normal and abnormal conditions have been determined. The conductors have to maintain the clearances under lightning, switching and TOV (temporary over voltage). According to the result in this project, the Top cross-arm is the most significant part of tower that is exposed to the impact of wind, because it is the highest in height and shortest in length. Therefore, the study referred to the top cross-arm, as the impact is also most significant on the horizontal clearances side, as the infringement of the safety and transient clearances can occur at a small swing angle $\left(27^{\circ}\right)$.

The chance of infringing the vertical clearances is almost zero because the swing angle should exceed $35^{\circ}$ to achieve that infringement. Therefore, even the effects of these two vertical clearances are ignored in this analysis.

In this project, Visio and Excel modelling are important because they provide key information about the characteristics of the $400 \mathrm{kV}$ transmission line tower for investigation and prediction of the wind impact on a L12 tower. The aim and objectives of this project have been mostly achieved. The Excel model can be used to study any type of tower, such as U2, L12 and U6. In this case, a L12 tower was used. Average Wind speed in Libya was the reference in this study case, and the characteristics of the L12 tower were used to find the wind impact on a L12 tower if installed in Libya.

\section{REFERENCES}

[1] IEC, "Insulation coordination part- 4: Computational guide to insulation co-ordination and modelling of electrical networks," 2004.

[2] IEC, "Insulation coordination part -1: Definition, principle and rules," 7 th edition, 1997.

[3] IEEE Guide for the Application of Insulation Coordination, IEEE Standard 1213.2, 1999.

[4] CIGRE, "Tower top geometry," CIGRE Working Group 22.06, June 1995.

[5] BSI, "Overhead electrical lines exceeding AC 45kV - Part 3: Set of National Normative Aspects,” BS EN 50341-3-2001, October 2001.

[6] BSI, "Loading and strength of overhead transmission lines," BS EN 7733:1994, April 1994.

[7] BSI, "Conductors for overhead lines - round wire concentric lay stranded conductors," BS EN 50182, August 2001.

[8] A. R. Hileman, Insulation Coordination for Power Systems. Boca Raton, USA: Taylor and Francis Group, LLC, CRC Press, 1999.

[9] P. Nefzger, F. Kiessling, J. F. Nolasco, and U. Kaintzyk, Overhead Power Lines - Planning, Design, Construction, Germany: Springer, 2003.

[10] BSI, "Live working - minimum approach distances for A.C systems in the voltage range $72.5 \mathrm{kV}$ to $800 \mathrm{kV}$ - a method of calculation," BS EN 61472, 2004. 
[11] CIGRE Working Group, "Guidelines for evaluation of the switching impulse strength of external insulation," CIGRE Technical Brochure $72,1992$.

[12] R. S. Guror, E. A. Cherney, and J. T. Burnham, Outdoor Insulator, Phoenix, Arizona USA: Ravi S. Guror Inc., May 1999.

[13] J. S. T. Looms, Insulator for High Voltages: Peter Peregrinus Ltd. London, United Kingdom, 1988.

[14] Central Electricity Generating Board (CEGB), Overhead Line Handbook, April 1989.

[15] GECOL, Design Standards for Libya, 2003.

[16] F. Kiessling, P. Nefzger, J. F. Nolasco, and U. Kaintzyk, "Overhead power lines planning, Design, Construction," Springer.

[17] Conductor Bundles for Overhead Lines, issue 1, October 2004, National Grid Transco.

[18] S. R. Krishnamurthy and P. Selvan, "Use of AAAC in a distribution network-a strategy for energy and cost reduction," 1995.

[19] S. N. Mohtar, M. N. Jamal, and M. Sulaiman, "Analysis of all aluminum conductor (AAC) and all aluminum alloy conductor (AAAC)," in Proc. IEEE Region 10 Conference on TENCON, 2004, pp. 409-412.

[20] Overhead Line Handbook.

[21] National Grid, "Internal and contract specific technical specification, insulator sets for overhead lines TS 3.4.17," issue 2, September 2006.

[22] Insulation Co-ordination. Computational Guide to Insulation Co-ordination and Modelling of Electrical, IEC60071-1, Part 1.

[23] Insulation Co-ordination. Computational Guide to Insulation Co-ordination and Modelling of Electrical, IEC60071-4, Part 4.

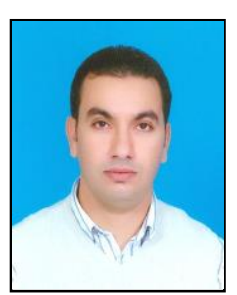

Ali I. El Gayar is a lecturer and the head of Control Department at College of Electrical and Electronics Technology-Benghazi-Libya. He is a Ph.D. student at UTM University. He obtained his bachelor's degree of electrical engineering from Benghazi University at Libya in 2005 . He had worked as a field engineer at Schlumberger Company from 2005 to 2006, and then he moved to Halliburton Oil Company to work as logging engineer from 2006 to 2009 . He joined UTHM university as master student and obtained his M.Sc. degree in electrical engineering in 2011 His research interests are high voltage, transmission line, power towers, induced voltages and lightning.

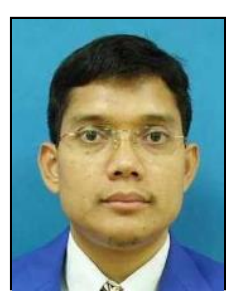

Zulkurnain Abdul-Malek is an associate professor and director at UTM Institute of High Voltage \& High Current (IVAT) Universiti Teknologi Malaysia obtained his M.Sc. degree in electrical and electromagnetic engineering with industrial applications in University of Wales Cardiff, Unitd Kingdom, 1995. He received his Ph.D. degree in high voltage engineering from Cardiff University, United Kingdom, 1999. He is the director in UTM Institute of High Voltage \& High Current (IVAT)/UTM High voltage. He is a member of Institute of Electrical and Electronics Engineer (MIEEE) and collective member of The International Conference on Large High Voltage Electric Systems (CIGRE). He has been the chairman of Working Group on High Voltage Test Techniques, Malaysia since 2009. He is member in Technical Committee on High Voltage Transmission, Malaysia, from 2009 till now, a member in Working Group on High Voltage Switchgear, Controlgear and Assemblies, Malaysia, form 2002 till now.

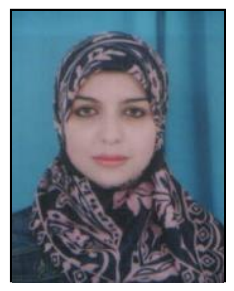

Ibtihal Fawzi El-Shami received the BSc. degree in electrical and electronics engineering from Benghazi University in 2006 and master degree in electrical engineering (EMC) from Universiti Tun Hussein Onn Malaysia (UTHM) in 2011. She is now a PhD student at the Faculty of Electrical Engineering, University Technology Malaysia as doctoral student. She is also a lecturer at College of Electrical and Electronics Technology-Benghazi-Libya. 